\title{
SUBJETIVIDADES E ASPIRAÇÕES: OS MOVIMENTOS DE JUVENTUDE NA ALEMANHA (1918-1933)
}

Claudine Haroche

\author{
Diretora de \\ Pesquisa do Centre \\ National de \\ Recherche \\ Scientifique \\ (CNRS), França. \\ Tradução: Jacy \\ Seixas \\ Professora da \\ Universidade \\ Federal de \\ Uberlândia (MG); \\ tradutora de \\ "Maneiras de ser, \\ maneiras de sentir \\ do indivíduo \\ hipermoderno" \\ (Agora, v.VII, n.2, \\ jul/dez 2004).
}

RESUMO: As sociedades contemporâneas apresentam formas paradoxais e inéditas de vínculo e de como se constituir em comunidade. A oscilação entre a fusão e o medo do contato, característica do modo de vínculo contemporâneo, traduz um deslocamento do espírito de corpo. Pretende-se, aqui, através da discussão dos modelos de comportamento e tipos de aspiração psicológica, afetiva e moral, presentes nas associações profissionais, nas confrarias e nos movimentos de jovens - e em particular por meio do estudo dos movimentos de juventude da Alemanha pós-guerra de 1914 - considerar os mecanismos de funcionamento das sociedades contemporâneas e alguns de seus fenômenos, tais como o culto à juventude, o espírito clânico e os movimentos sectários.

Palavras-chave: Espírito de corpo, movimentos de juventude, comunidade estética.

ABSTRACT: Subjectivities and aspirations: the movements of German youth (1918-1933). The contemporary societies present paradox and new forms of links and of how to construct itself in a community. An oscillation between fusion and fear of contact, characteristic of the way of the contemporary link, translates a displacement of the body's spirit. It is intended, here, through the discussion of contemporary models and types of psychological aspiration, affectionate and moral, present in the professional associations, in the brotherhood and youth movements - and in particular by the ways of studying the German youth movements post 1914 war — to consider the functional mechanisms of contemporary society and some of its phenomenons, such as the youth cult, the brotherhood spirit and the sectarian movements.

Keywords: Body's spirit, youth movement, aesthetic community. 
“Formar seitas de fanáticos e jamais verdadeiras comunidades (...) Seria muito inquietante se cada professor que ocupa uma cátedra [na universidade] tivesse o sentimento de se defrontar com a exigência de mostrar que é um chefe." (Weber, 1919)

"Não é, portanto, sem razão que o sentimento público experimenta um distanciamento cada vez maior em relação ao diletante e aos homens que, apaixonados exclusivamente pela cultura geral, se recusam a se deixar prender nas teias da organização profissional. É que, com efeito, eles não se importam com a sociedade ou, se preferirmos, a sociedade não se importa com eles, eles escapam dela e precisamente porque não a sentem com a vivacidade e continuidade necessárias não têm consciência de todas as obrigações que sua condição de ser social lhes impõem." (Durkheim, 1893)

E m 1938, logo após a conferência de Elie Halévy sobre a “era das tiranias” (1938/1990), Marcel Mauss lhe escreve uma longa carta, na qual afirma "reconhecer com facilidade acontecimentos, como eles freqüentemente se passaram na Grécia, tão bem descritos por Aristóteles, acontecimentos característicos das sociedades arcaicas e talvez do mundo inteiro. É a "sociedade dos homens", com suas confrarias a um só tempo públicas e secretas, e no interior da sociedade dos homens a sociedade dos jovens que age." Escreve Mauss: "Sociologicamente talvez seja uma forma necessária de ação, mas se trata de uma forma obsoleta. Ela satisfaz à necessidade de segredo, de influência, de ação e juventude e com freqüência de tradição" (apud HOLLIER, 1995, p.849).

Naquelas poucas linhas, referindo-se à sociedade de homens, de jovens e à necessidade de ação e influência, Mauss toca em elementos fundamentais constituintes do "espírito de corpo". Pretendemos aqui aprofundá-los, colocando em discussão os modelos de comportamento e tipos de aspiração psicológica, afetiva e moral presentes, de forma mais ou menos acentuada, nas associações profissionais, nas confrarias e nos movimentos de jovens. ${ }^{1}$ (Utilizamos o termo 'espírito de corpo' em seu sentido genérico de 'espírito de grupo', que, em certos aspectos, se confunde com o ‘espírito comunitário', o ‘espírito tribal' e ‘clânico' e também com o ‘espírito sectário’: FREUD, 1921/1997).²

\footnotetext{
${ }^{1}$ É importante assinalar que as associações profissionais ou os movimentos de juventude, no entanto, não desenvolvem todas as atitudes e valores hoje inquietantes.

${ }^{2}$ Ver, também, Enriquez (1999), que argumenta que "todo grupo conhece um dia a tentação da comunidade (...). Este momento comunitário parece-me indispensável porque permite que todos os membros do grupo se apóiem uns sobre os outros e sobre o próprio grupo. Por outro lado, o grupo se fixa nesta etapa, em breve ele não é mais capaz da mínima ação capaz de colocar em questão seu equilíbrio. O conformismo dos sentimentos torna-se a regra, a submissão idealizada ao grupo (...) a única possível. E mais inquietante ainda é o crescimento de uma metáfora comum, a do corpo pleno, sem falha, sem carência, sem temporalidade (...)”.
} 
Mas, de que forma o estudo dos movimentos de juventude, particularmente os da Alemanha pós-guerra de 1914, seu caráter apolítico ou sua politização pronunciada, seus mecanismos de funcionamento, aspirações e modelos de comportamento podem contribuir para a compreensão dos mecanismos de funcionamento das sociedades contemporâneas? Esses movimentos — que se desenvolveram numa atmosfera marcada pelo recalque e rejeição e mesmo pelo ódio endereçado à velhice, pela negação dos limites revelada na busca obsessiva de juventude, no amor por aquilo que é jovem — possuem especificidades capazes de esclarecer certos fenômenos contemporâneos, como o juventudismo (o culto à juventude), o espírito clânico, os movimentos sectários.

\section{I}

O que o corpo — entendido no sentido de grupo, confraria, ${ }^{3}$ comunidade provoca nos indivíduos, em seus corpos e espírito, sua maneira de ser e de viver? Ele os força a determinados comportamentos, envolvendo-os, protegendo-os e de certa forma servindo de apoio, incitando-os à superação de si mesmos pela abnegação e renúncia aos interesses privados, pela sensação e vontade de poder e mesmo pelo conformismo e submissão ao grupo, por medo ou angústia. O corpo repercute sobre o corpo individual e a personalidade individual (HAROCHE, 2004a).

O que certas formas de comunidade estimulam na personalidade? A força, o poder, a energia, a lealdade, a submissão, a ausência de senso crítico. E, ao contrário, o que é apagado do 'eu’? O senso crítico, a reflexão, a recusa, o desacordo, a independência de espírito, a rebelião, a revolta. O que deixamos desenvolver em nome da coletividade e da sociedade por ideal ou complacência, inconsciência ou mesmo niilismo?

Dois modelos de comportamentos e de tipos de aspiração aparecem com clareza, mesmo se às vezes indistintos: a aspiração à superação de si não tem a mesma significação e não responde a valores idênticos na moral republicana e na

\footnotetext{
3 É interessante observar a evolução da etimologia a palavra "irmão" (frère) na língua francesa, de onde deriva irmandade, confraria (confrérie): "Desde o francês antigo (c. 1050) a palavra se aplica ao homem como membro da 'família' humana, particularmente em religião (1690), referindo-se aos homens como criaturas do mesmo deus. 'Irmão' designa (c. 1175) os membros de certas comunidades religiosas e é o nome como os franco-maçons se tratam entre si (1164). Por extensão, 'irmãos' no plural aplica-se, como no latim, ao homem em relação àqueles que compartilham com ele dos mesmos sentimentos, interesses (...) 'irmãos de arma' designou (metade do século XV) os guerreiros unidos entre si por um aliança e aplica-se hoje àqueles que lutam pela mesma causa, aos membros de uma associação." Cf. verbete "frère" do Dictionnaire historique de la langue française Robert. As relações entre irmão, aliado e normas, leis e princípios de funcionamento participam das relações complexas e mutáveis entre "espírito de família" e "espírito de corpo".
} 
comunidade emocional dos movimentos de juventude, nos agrupamentos profissionais. Eles diferem em sua relação com o limite: o respeito, a ignorância mais ou menos deliberada e repetida, a transgressão sistemática. Mecanismo complexo, que, em sua ambigüidade, pode se tornar ameaçador, revelando dois tipos de aspirações: o desejo e a necessidade de proteção, de apoio, que conduz à associação, à corporação, e que implica numa abnegação capaz de ser racional, regulada pela coletividade. Pode, por outro lado, conduzir à comunidade emocional, fusional, à anulação deliberada de si mesmo, desejada ou imposta, ao sacrifício do eu em nome da coletividade. Às vezes imbricadas e mesmo indiscerníveis, as duas tendências revelam permanências fundamentais do político. ${ }^{4}$

Algumas destas questões foram formuladas em contextos históricos diversos: por Durkheim que, em estudos dedicados aos grupos profissionais e à solidariedade, procurou contribuir com as bases da república, da democracia social, buscando afastar os perigos da "anomia”. Estas questões estão igualmente presentes nos escritos de Weber que, desencantado, pessimista, discerne a existência de um profundo mal-estar revelando certa desconfiança quanto à natureza do vínculo social.

Tais interrogações foram colocadas, de maneira intensa, em 1933, pelos movimentos de juventude na Alemanha, as confrarias. Hoje em dia, elas reaparecem sob prismas igualmente intensos e, sob alguns aspectos, inéditos, em certas formas de comunitarismo, integrismo, fundamentalismo e seitas. Nas sociedades

\footnotetext{
${ }^{4}$ Legendre (1996, p. 22-24) aborda esta questão da superação e do limite: "fabricar o homem é dizer-lhe seus limites, ensinar-lhe um 'além' de sua pessoa, é separar o homem de si mesmo. (...) Cada civilização produz seu estilo de educação considerando esta separação.” O espírito de corpo representa uma forma específica de separação e de associação dos indivíduos em grupo: quando deslocado pode se tornar um lugar de fusão, de ausência de limites. Legendre (1999) percebe no nazismo e na Shoah "a derrota do princípio normativo do limite" e alerta para o fato de se "renunciar a analisar as decorrências institucionais da Shoah, a saber, a dessimbolização generalizada de que são vítimas as novas gerações do Ocidente". Identifica, aqui, "os efeitos de um hitlerismo sem nome (...) um neototalitarismo de feitura liberal [que] transmite ao cerne da civilização de direito civil a ideologia da ausência de limites." A recusa dos limites e da lei constitui o centro da análise que Emmanuel Diet (1999a) faz dos mecanismos sectários. O autor descreve com precisão os mecanismos sectários, que hoje em dia não cessam de se expandir com o isolamento e a precarização crescente dos indivíduos: "as organizações sectárias (...) exigem a adesão incondicional ao seu discurso de certezas; elas isolam e proíbem a seus adeptos todo contato com o mundo exterior e seus valores, exceto aqueles com finalidade de proselitismo e infiltração (...), todas as seitas têm necessidade, para assegurar seu domínio, de impor a seus adeptos uma dessocialização e deculturação. (...) A tentação e a possibilidade de uma deriva sectária estão presentes em todo grupo ideológico: o isolamento dos adeptos, a recusa de toda alteridade e diálogo, o fechamento do grupo sobre si mesmo, a proibição de toda crítica e relação com o mundo exterior, a recusa e negação dos valores e leis que estruturam o campo social e cultural, o domínio totalitário de todos os aspectos da vida do sujeito e a vontade de controlar seu pensamento e desejo, a destruição dos vínculos de pertença anteriores, tudo isso permite caracterizar a violência específica ao ódio e destrutividade sectárias" (p. 53-54).
} 
individualistas contemporâneas, as questões relativas à superação e engrandecimento de si apresentam modos de funcionamento paradoxais, nas quais fusão e exclusão podem vir juntas: mecanismos de exclusão e rejeição exacerbada e ao mesmo tempo ignorância e recusa de se relacionar com o limite; exclusão do outro, da alteridade e fusão com os corpos dos outros na ignorância da especificidade do eu de cada um, das pessoas, da singularidade e da especificidade de cada indivíduo. Afinal, o que se funde? Os corpos e os espíritos em um todo que os ultrapassa? O que é excluído e negado? A singularidade de cada um, sua capacidade de reflexão e de recusa?

Estas questões nos instigam a desenvolver a reflexão sobre os grupos, a identidade, a "ilusão grupal". ${ }^{5}$ Trata-se de um aspecto crucial que opera na idéia mesma de comunidade, no desenvolvimento simultâneo de formas extremas de individualismo e de espírito clânico: a aspiração ao vínculo, à sua proteção e calor podem ser compreendidos como algo que vem preencher um déficit de laços, oriundo do isolamento e do caráter impessoal da lei na democracia (em relação à igualdade). As sociedades democráticas individualistas contêm uma distância, instauram a impessoalidade, reforçam uma frieza irredutível, capaz de explicar, por um lado, o desenvolvimento de uma atmosfera de radicalidade, de ideais negativos, de niilismo, de movimentos integristas, que, assim, respondem aos fenômenos de anomia, de ausência de referências, de incertezas e angústias presentes nas sociedades contemporâneas. ${ }^{6}$

\footnotetext{
${ }^{5}$ Ginzburg (1986/1989) colocou questão análoga em relação às fronteiras do eu, à ausência de limites em certos tipos de associação, de comunidade, durante o Terceiro Reich, que exprimiam um interesse e cuidados exclusivos com o corpo e as sensações, que valorizavam os jovens, culminando naquilo conhecido como jeunisme (juventudismo). Sublinhando a atualidade desta questão, Ginzburg interroga-se sobre a existência "de uma comunidade ideológica entre a mitologia indo-européia em sua vertente germânica e as realidades políticas, sociais e institucionais do Terceiro Reich" (p.193).

${ }^{6}$ As redes comunitárias no mundo contemporâneo aparecem como formas inéditas do espírito clânico, paradoxal e frio. É precisamente esta dimensão que Bauman (2001, p.1-2; 2003, p.7-8) procura esclarecer: "As palavras têm significado: algumas delas, porém, guardam sensações. A palavra 'comunidade’ é uma delas. Ela sugere coisa boa: o que quer que 'comunidade’ signifique, é bom 'ter uma comunidade’, 'estar numa comunidade’. (...). As empresas ou a sociedade podem ser más; mas não a comunidade. A comunidade, sentimos, é sempre uma coisa boa. (...) a comunidade é um lugar 'cálido', um lugar confortável e aconchegante. É como um teto sob o qual nos abrigamos da chuva pesada, como uma lareira diante da qual esquentamos as mãos num dia gelado. Lá fora, na rua, toda espécie de perigo está à espreita (...). Aqui, na comunidade, podemos relaxar (...) numa comunidade podemos contar com a boa vontade dos outros. Se tropeçarmos e cairmos, os outros nos ajudarão a ficar de pé outra vez."
} 


\section{II}

Durkheim publica, em 1893, Da divisão do trabalho social, livro muito importante para a nossa reflexão, no qual aborda fragmentos de uma história das corporações, contribuindo para a compreensão dos fundamentos da democracia social, do solidarismo. No prefácio à primeira edição, esclarece que a questão central de que se ocupa “é a das relações entre a personalidade individual e a solidariedade social (1978a, p.XLIII)." Mas, ao redigir o prefácio à segunda edição, trata o problema de um ângulo diferente: não mais enfatizando as relações entre personalidade individual e solidariedade social, mas os agrupamentos profissionais, afirmando que "a corporação é chamada a se tornar a base ou uma das bases essenciais de nossa organização política” (1978b, p.XXXI ). Enfatiza a necessidade das corporações, dos agrupamentos profissionais que "respondem a necessidades duráveis e profundas”. Eles exercem intensa influência moral, instauram certo tipo de vínculo, são capazes de "manter no coração dos trabalhadores o sentimento vivo de sua solidariedade comum, impedir que a lei do mais forte se aplique tão brutalmente" (idem, p.XII ). ${ }^{7}$

O autor detalha a atmosfera reinante nas corporações romanas: "mesmo nas corporações operárias, associava-se antes de tudo pelo prazer de viver junto", escreve, remetendo-se a Boissier: "para encontrar fora de casa distrações às fadigas e aborrecimentos, criar uma intimidade menos restrita que a família, menos extensa que a cidade e tornar assim a vida mais fácil e agradável” (BOISSIER apud DURKHEIM, 1978b, p.XIV). Sublinha que "a vida comum é atrativa e ao mesmo tempo coercitiva. O constrangimento é necessário para levar o homem a superar-se a si mesmo" (DURKHEIM, 1978b, p.XVII).

Todos os termos são aqui relevantes. Podemos, entretanto, resumi-los assim: as pessoas se associam para se superar, é a associação que efetivamente permite a superação de si. Para Durkheim, a superação de si se faz em nome da moral republicana democrática. Ele vê na associação a condição da possibilidade de bem-estar e de proteção, em nome da comunidade, da vida moral: a associação oferece as condições de uma superação moral e psicológica de si.

"Quando indivíduos que acham ter interesses comuns se associam não é apenas para defenderem estes interesses, é para não mais se sentirem perdidos em meio a adversários, para sentirem o prazer de comungar, de serem um em muitos, quer dizer, para levarem uma mesma vida moral.” (idem, p.XVIII)

\footnotetext{
${ }^{7}$ Durkheim detém-se na evolução do papel das corporações na história: "enquanto que em Roma ela [a corporação] começou quase fora dos quadros normais, ela serviu, ao contrário, de quadro elementar em nossas sociedades atuais (...) posto que a comuna era uma reunião de corporações e se formou seguindo o tipo da corporação, é esta, em última análise, que serviu de base a todo o sistema político oriundo do movimento comunal” (p.XX).
} 
Esta superação que impede o isolamento do indivíduo, que implica em alguma renúncia de si e desencoraja o egoísmo é, portanto, fundamentalmente moral. Durkheim enfatiza — ainda aqui todos os termos são importantes — que um grupo: “... não é somente uma autoridade moral regendo a vida de seus membros (...) ele libera um calor que aquece e reanima os corações, que os abre à simpatia, derrete os egoísmos” (p. XXX).

Define, então, não apenas os fundamentos do espírito de corpo, mas de toda moral:

“...a subordinação da utilidade privada à utilidade comum qualquer que ela seja tem sempre um caráter moral, pois implica necessariamente em algum espírito de sacrifício e de abnegação. Estas prescrições [procedem] de sentimentos morais que são ainda os nossos" (p.XV).

Considera, no entanto, a possibilidade de degenerescência e desvio de toda instituição: as regras podem se tornar "inutilmente persecutórias", os mestres "se preocuparem muito mais em salvaguardar seus privilégios do que velar pelo bom nome da profissão e honestidade de seus membros” (p. XVI ).

Esta superação moral de si, que assegura também o prazer de estar junto, não tem, para Durkheim, nada de inquietante. A superação de si se faz para ele em nome da moral republicana democrática. Este traço revela-se fundamentalmente diverso daquele pressentido por Weber nos movimentos de juventude. Em 1919, Weber vai se sensibilizar com outros aspectos das corporações, das comunidades, dos movimentos de juventude, com as possibilidades de deriva do espírito de corpo, com o aspecto ameaçador que eles podem conter e esconder.

Weber descreve e resume em poucas linhas a emergência dos movimentos de juventude, mostrando-se sensível à atmosfera da época, à racionalização, ao clima de desencantamento. E lembra, assim como Durkheim, a necessidade durável dos pequenos círculos, das comunidades, das relações de homem a homem. Quando Durkheim falava de corporações, de agrupamentos profissionais, da superação moral de si, Weber, em Ciência e política: duas vocações vai se ater, tomando o exemplo das universidades, dos movimentos de juventude e das confrarias universitárias, nos fenômenos ambíguos capazes de se transformar em ameaças à sociedade democrática: a busca do corpo-a-corpo, a anulação das distâncias, o declínio das mediações que acompanham o culto do chefe em uma busca de superação, de transcendência e de fusão (WEBER, 1919/1982). ${ }^{8}$

\footnotetext{
${ }^{8}$ Ver, igualmente, Freud (1921, apud DIET, 1999) ao enfatizar a especificidade dos fenômenos sectários, chama a atenção para as dimensões ameaçadoras deste deslocamento do espírito de corpo. Insiste sobre o fato de que as seitas com suas práticas destroem a função simbólica e instauram uma violência que leva a uma incapacidade de simbolização massiva e insidiosa; é
} 
Alertando contra a mitificação, Weber tece comentários aos quais devemos hoje dar a maior atenção: fala de um fenômeno que "consiste em algo de muito sério e sincero, ainda que, muitas vezes, interpretemos falsamente sua significação. Quero falar dos movimentos de juventude que se desenvolveram ao longo dos últimos anos com o objetivo de dar às relações pessoais, no interior de uma comunidade, o sentido de uma relação religiosa, cósmica ou mística” (idem, p.95-96). Estamos, escreve Weber, em uma “época caracterizada pela racionalização, intelectualização e, sobretudo, pelo desencantamento do mundo, [o que] levou os humanos a banirem os valores mais elevados e sublimes da vida pública”. Ora, estes valores supremos, os valores de fraternidade e cordialidade, de apoio e proteção que os movimentos de juventude tentam precisamente reinstituir “encontraram um refúgio seja no reino transcendente da vida mística, seja na fraternidade das relações diretas e recíprocas entre indivíduos isolados. Não há nada fortuito (...) no fato que hoje em dia encontremos unicamente nos pequenos grupos comunitários, no contato homem a homem, algo que corresponda ao profético que inflamava outrora as grandes comunidades e as mantinha unidas" (idem, p.96).

Weber pressente o lado extraordinariamente ameaçador destes movimentos de juventude, das confrarias universitárias, de seus modelos de comportamento e tipos de aspiração que exigem — ou valorizam — as qualidades de chefe no professor, e que não tem mais nada a ver com aquelas descritas por Durkheim: trata-se, agora, da comunidade emocional e do culto do chefe. Escreve Weber:

"Vocês vêm aos nossos cursos exigindo de nós, que somos seus professores, qualidades de chefe sem jamais pensarem que, de cada cem professores, noventa não têm nem devem ter a pretensão de ser campeões de futebol (...) nem 'chefes' nas tarefas que dizem respeito à conduta de nossa vida. Não se deve esquecer que o valor do ser humano não depende necessariamente das qualidade de chefe que ele pode possuir

essencial, portanto, "marcar sua especificidade em relação aos movimentos religiosos, filosóficos ou associativos com os quais as seitas esforçam-se por se confundir (...)." Opondo-se à posição de certos historiadores ou sociólogos das religiões que se atêm ao discurso manifesto sem examinar as práticas e suas conseqüências, banalizando e minimizando o fenômeno sectário sob a denominação de "novos movimentos religiosos", Diet afirma que é preciso considerar a singularidade histórica das "novas seitas”, irredutíveis a meros "grupos minoritários, heréticos ou exóticos (...). Tendo fracassado em sua vontade de sujeição ao mesmo, agitadas pela história, aceitando um certo pluralismo e o diálogo com a racionalidade científica, as grandes doutrinas e associações filosóficas e religiosas instituem leis e interditos com vocação universal aos quais sacerdotes e crentes se submetem de maneira igual, enquanto que a lógica sectária (...) justifica todas as violências contra aqueles que se opõem às ações do grupo e criticam sua doutrina. Mesmo se a interdição de pensar está sempre presente, as religiões, apoiadas em seu dogmatismo, asseguram uma função simbólica" (grifo nosso, DIET, 1999b, p.52-53). 
ou não. De qualquer forma, as disposições que fazem de um homem um cientista eminente e um professor universitário certamente não são as mesmas que poderiam fazer dele um chefe na conduta prática da vida (...).”

E conclui: "seria muito inquietante se cada professor que ocupa uma cátedra tivesse o sentimento de estar colocado face à exigência de mostrar que é um chefe" (idem, p.87).

A pretensão, a aspiração à superação de si não é aqui a mesma: não se trata mais do caráter atrativo e do bem-estar proporcionado pela vida numa associação ou num grupo profissional, da dedicação e abnegação de cada indivíduo à sociedade, da renúncia moral a si mesmo. Trata-se agora da eventualidade do fanatismo e da radicalização, do culto do chefe. Weber previne: “As profecias que saem das cátedras universitárias não têm outro resultado senão o de formar seitas de fanáticos e jamais verdadeiras comunidades" (idem, p.96).

Os estudos de Lacqueur (1997) e de Gay (1993, 1995) sobre as fraternidades, as corporações, os movimentos de juventude nos possibilitam precisar certos aspectos e distinguir a comunidade de pertença, fundamental e necessária, da comunidade fusional.

III

Estas análises sublinham, nos movimentos de juventude, a importância atribuída à idéia de comunidade emocional indizível: a superação de si manifesta-se no engajamento apaixonado e confuso, na exaltação e desejo de fusão que se apóiam implicitamente, e mesmo explicitamente, em ideais viris, acompanhados com freqüência de um profundo desengajamento político. Escreve Lacqueur: "Cada um atribuía importância considerável ao espírito de grupo, importância sentida confusamente, mas expressa com fervor nas excursões, cantos, fogueiras, vendo nisso experiências que visavam restaurar os laços primitivos" 9

Todos estes movimentos, que apresentam diferenças importantes ao pregar os ideais de uma comunidade orgânica autêntica, colocavam a tônica na vida coletiva e tinham uma concepção determinada da natureza dos vínculos entre os indivíduos no grupo. Valorizavam “a abnegação e a aptidão ao comando”, a lealdade, qualquer que seja seu conteúdo, e a devoção ao chefe. Além disso, apareciam como respostas ao medo da fragmentação materialista, às formas arcaicas de angústia anteriores à função simbólica presente em toda sociedade. O que auxilia a compreender por que "estes movimentos sempre foram extremos, descompromissados, emocionais, entusiastas: eles nunca foram moderados e racionalistas"

\footnotetext{
9 Lacqueur distingue na história dos movimentos de juventude uma primeira fase, a dos wandervogel, que se estende de 1896 a 1919, da fase do Bund, que termina em 1933.
} 
(idem, p.VI). Exprimiam, enfatiza Lacqueur, uma oposição apolítica a uma civilização que "tinha pouco a oferecer às jovens gerações: eles significavam um protesto contra a falta de vitalidade, entusiasmo, emoções e ideais. Aspiravam a desenvolver o contato fusional” (idem, p.VII).

Pouco importa se uns fossem "revoltas contra a repressão das emoções individuais" e outros expressões de patriotismo contra o autoritarismo prussiano ou a revolução francesa: o fato de participar de lutas comuns que revelassem uma mentalidade guerreira e belicosa era essencial. Todos eles criticavam o mundo dos adultos e proclamavam uma valorização da juventude como tal: "O movimento era pré-liberal, romântico e, sob certos aspectos, medieval (...). A única maneira de restaurar uma sociedade harmoniosa era se conformar o mais rigorosamente possível aos modelos de comportamento da Idade Média, com senhores e vassalos" (idem, p.3).

A diferença em relação aos grupos profissionais evocados por Durkheim é evidente: seus membros eram honestos, "pretendiam-se puros, leais com seus camaradas e corajosos", mas estes movimentos de forma alguma os preparavam para "uma cidadania ativa". Seus professores e chefes ensinavam-lhes latim e grego, mas "em geral deixavam de lhes ensinar que as humanidades significavam também a crença nos direitos do indivíduo e na dignidade, não unicamente os direitos dos membros de seu grupo particular, mas de todo o ser humano" (idem, p.41).

Peter Gay, em O cultivo do ódio, desenvolve e detalha as idéias de Lacqueur. Precisa os contextos social, psicológico e político do aparecimento dos movimentos de juventude (GAY, 1997). ${ }^{10}$ Lembra que "os homens sentiam-se obrigados a demonstrar, desde a idade da adolescência (...), qualidades viris, ousadia, força física e resistência ao esforço e ao sofrimento". Eles aspiravam a se tornar homens duros e fortes. O prestígio constituía o sentido e a finalidade última de sua existência. Estes jovens temiam o fracasso e "continuamente em situação de prova, viam-se coagidos a adotar uma atitude belicosa em face de rivais e eventuais adversários" (idem, p. 121,122, 123).

Nos trabalhos em que analisa a República de Weimar, Peter Gay estuda os modelos de comportamento alemães, vendo neles duas dimensões, dois tipos

\footnotetext{
${ }^{10}$ Gay (1997) analisa a valorização da coragem, da força, da energia que, no século XIX, se torna um verdadeiro culto da força e da virilidade. Lembra, assim, que "em 1906, o sociólogo francês Georges Sorel se lamentava da moleza da classe média (...) mais preocupada em se engajar em ações humanitárias do que na luta" (p.109). Ressalta que "em 1895, em seu discurso de admissão à Academia Francesa, o romancista e ensaísta Paul Bourget declarou que o espírito moderno sofria de atrofia da vontade e que tinha sido atingido por uma crise de niilismo e pessimismo" (p.108). E prossegue: "longe de ser uma invenção da época moderna, atestava a reminiscência dos ideais aristocráticos e os da Grécia antiga” (p.107). E conclui afirmando que "o ideal viril se revela um mecanismo incerto destinado a facilitar a liberação das pulsões agressivas" (p.107).
} 
distintos de preocupação: a do "auto-aperfeiçoamento, a bildung (...) livre de toda política, e aquela, inferior e sórdida, dos assuntos humanos, com seus compromissos e questões de ordem prática” (GAY, 1968/1995, p.98).

A coexistência entre estes dois tipos de valores vai se desenvolver em uma combinação específica de ingenuidade, estupidez adolescente e pragmatismo maquiavélico e sádico. Os wandervogel, escreve Peter Gay:

\footnotetext{
“buscavam na cordialidade e camaradagem um escape às mentiras engendradas pela cultura da pequena burguesia, um modo de vida sadio (...) e, sobretudo, uma existência em comum, capaz de se elevar acima dos interesses particulares e da política mesquinha dos partidos."
}

Nesses movimentos havia chefes e discípulos que utilizavam uma linguagem e um estilo específico, elemento e imagem de "sua intimidade emocional”, e celebravam certas palavras, como, por exemplo, gemeinshaft: a comunidade era a seus olhos uma invocação mágica”. As aspirações e valores dos wandervogel exprimiam “sua busca de alma, sua desconfiança em relação ao espírito” (p.105).

Para falar do complexo de sentimentos e reações que exprime o espírito deste movimento de juventude, vale-se da expressão "busca de unidade", que representa, em seu ponto de vista, uma regressão oriunda de um grande medo: “o medo da modernidade”. Segundo Gay, as abstrações que Tönnies e outros utilizaram, como volk, führer, organismus, reich, entscheidung, gemeinshaft, aufheben (termo hegeliano que significa ao mesmo tempo 'elevar', 'anular' e 'preservar'), 'revelam uma necessidade desesperada de raízes e pertença a uma comunidade, constituem uma rejeição radical da razão, a que se acrescenta o apelo à ação direta ou à submissão a um chefe carismático". Observa que "este conglomerado de sentimentos hostis que se fazia passar por filosofia” incitou Troeltsch, em 1922, a assinalar o perigo desta inclinação, a seus olhos especificamente alemã, que favorecia a "mistura de misticismo e brutalidade" (idem, p.123, 124). ${ }^{11}$

IV

Retomemos a carta de Mauss, que evoca o tipo de ação obsoleta, arcaica ("regressiva”, diria Freud), da sociedade de jovens na “sociedade dos homens”. Indo

\footnotetext{
${ }^{11}$ Peter Gay detém-se em aspectos que nos parecem decisivos: “aqueles que nos anos 1920 buscavam integração e unidade não cederam todos à tentação da regressão (...). Recorrendo à razão mais do que ao irracionalismo, não por niilismo mas pela construção, e este último termo dever ser considerado literalmente, pois são os arquitetos que formularam esta filosofia moderna e democrática em seus escritos e a colocaram em prática em seus edifícios" (idem, p.125). Ver, também Dumont (1991, p.61), a propósito de bildung, “a idéia alemã de liberdade, segundo Ernst Troeltsch".
} 
ao encontro das análises de Lacqueur e de Gay, também Bourdieu, em 1989, debruça-se sobre o espírito de corpo, enfatizando "os laços afetivos intensos e duráveis de fraternidade que se instauram necessariamente entre os adolescentes das universidades" (1989, p.257; 1994, p.123-131). Conclui sua análise com um comentário que merece ser retomado e aprofundado:

“o amor é sempre, assim como a 'fraternidade' ou a 'sororite' 12 escolar, a manifestação de uma forma particular de espírito de corpo (...) o amor de si nos outros e no grupo favorecendo a reunião prolongada de semelhantes é o verdadeiro fundamento do que chamamos 'espírito de corpo' (do qual o espírito familiar é um caso particular)." (BOURDIEU, 1989, p.257-258)

Os sociólogos alemães Tönnies, Weber, Reich, Adorno, Elias, e também a psicanálise com Freud (1921-1999; 1930/1995) abordaram estas questões desde o final do século XIX. Hoje, elas se recolocam de maneira problemática e urgente. O que teria mudado nos modelos de comportamento e aspirações neste tipo de associação, nos movimentos de juventude e, mais amplamente, nos tipos de comunidade contemporâneas? E, ao contrário, o que teria permanecido ao longo das épocas, sistemas, mudanças e transformações?

Todos as análises foram sensíveis ao caráter potencialmente ameaçador destas formas de associação, na medida que admitiam, instauravam e encorajavam uma tendência favorável não à seita, no sentido estrito do termo, mas ao espírito e mentalidade sectárias. Ao lembrar a organização extremamente formal, hierarquizada e autoritária das primeiras associações de estudantes, as confrarias nacionalistas, Elias as compara aos comportamentos dos estudantes que, nos anos 1980, tendiam a formas de organização mais igualitárias: ele temia que estes estudantes não fossem capazes de evitar a ressurgência das hierarquias (ELIAS, 1996, p.38). Enfatizava, pensando na República de Weimar, que as pessoas haviam acreditado “que uma democratização dos comportamentos, das crenças e das convicções acompanharia naturalmente a instalação das instituições democráticas parlamentares”, mas os fatos revelaram uma busca permanente de organização e hierarquia (idem, p.337).

Reich desenvolveu a propósito da psicologia de massas do fascismo uma análise profundamente esclarecedora das confrarias, dos movimentos de juventude na Alemanha, sublinhando a estrutura de caráter aí instaurada, encorajada e imposta. Escreveu que:

\footnotetext{
12 Sororité, em francês, significa a solidariedade feminina. O termo vem da combinação do
} latim soror e do inglês sorority remetendo à freternité (fraternidade). (N. da T.) 
“a atualização da estrutura de caráter era uma tarefa essencial de toda democracia, que não poderia se limitar à supressão de instituições ditatoriais e autoritárias, que não poderia se limitar à instalação de instituições novas, pois estas instituições degenerariam infalivelmente em outras instituições ditatoriais e autoritárias: era preciso esforçar-se para suprimir, ou ao menos reduzir, a fixação do caráter do absolutismo autoritário nas massas."

A questão fundamental que, desde 1917, se colocava à psicologia de massas era saber se, escrevia Reich, “a nova ordem socioeconômica da sociedade russa se reproduziria, e de qual maneira, na estrutura de caráter dos homens? O homem novo soviético seria liberal, antiautoritário, racional e transmitiria estas qualidades a seus filhos?” (REICH, 1998, p.198; ADORNO, 1950/1998).

Parece-nos, hoje, decisivo retomar e aprofundar estas idéias, levando em consideração as mudanças na personalidade e estrutura de caráter do indivíduo contemporâneo. Procurar, assim, ir além do caráter autoritário e rígido presente na análise de Reich e interrogar-se sobre a instabilidade e inconsistência de caráter, focando novamente a questão da energia e ebulição. ${ }^{13}$ Com efeito, estes tipos de personalidade e de caráter estão presentes de forma aguda em tipos de associação que as encorajam e das quais emergem, na natureza dos laços que fomentam, nos comportamentos e atitudes que incitam e nos tipos de valores e atividades que promovem.

Recentemente, Bauman buscou compreender a natureza, o funcionamento e o desenvolvimento das comunidades contemporâneas no contexto da globalização (BAUMAN, 2001, p.XX). Insistiu sobre a necessidade profunda e irredutível de pertença, sobre o fato de que esta necessidade tem aumentado, tornando-se sempre mais intensa, a ponto de paulatinamente substituir os direitos e deveres de cidadania pelas expressões — e reivindicações — identitárias. Ao ilustrar o caráter complexo e eminentemente problemático de uma 'comunitarização' das sociedades contemporâneas, Bauman nos leva a repensar a diferença entre comunidade ética, da qual falava Durkheim, e o caráter ameaçador da comunidade emocional, evocada por Weber. ${ }^{14}$ Vai, no entanto, além deste aspecto, discernindo uma comunidade específica às sociedades contemporâneas, a "comunidade estética”, que instaura e promove tipos de laços, de vínculos, que não engajam.

Fixando-se nos modelos de comportamento que podem transformar a natureza dos vínculos, as formas de associação e reunião e provocar dessubjetivação,

\footnotetext{
${ }^{13}$ Ver, entre outros, Bouhsira et al. 2004.

${ }^{14}$ Bauman afirma que "os engajamentos que fazem com que uma comunidade seja ética são do tipo fraternal (...), ou seja, aquilo que os indivíduos de forma verossímil esperam da comunidade é uma garantia, uma promessa de certeza, de segurança e de proteção”, acrescentando que é precisamente deste aspecto "de que estão mais privados quando isolados" (2001, p.72).
} 
Bauman faz-nos perceber a dimensão superficial e festiva, descontínua e instável destes grupos. Refere-se, então, a certos aspectos da comunidade estética de Kant: “o governo dos comportamentos responde hoje a critérios mais estéticos que éticos. Não se conforma mais à autoridade moral dos líderes, a seus ideais, mas, sobretudo, ao comportamento de personalidades midiáticas” (idem, p.66). ${ }^{15}$

Bauman conclui afirmando a dimensão paradoxal e inédita de uma "comunidade de não-pertença”, definida como uma reunião de indivíduos isolados. Estes indivíduos se tranqüilizam com o fato de que estar só significa estar acompanhado e que lutar por si mesmo pela existência significa constituir uma comunidade.

Os ideais da comunidade estética são contrários aos ideais de uma comunidade ética, pois induzem à confusão entre espírito e corpo, desenvolvendo formas extremadas de narcisismo que tendem a afastar as dimensões estruturantes do espírito de corpo, definidas pela relação com o corpo. A primeira instaura modos de inclusão e de supressão, uma continuidade implícita, não simbolizada, entre os corpos; constrói corpo e aparência marcados pela sensação, a ausência de duração dos vínculos, a instantaneidade, a brevidade dos encontros, a descontinuidade. Na comunidade estética, a negação dos limites presente na dimensão festiva induz à superficialidade dos laços, ao desengajamento e ao declínio do sentido, acarretando então a dispersão, a fragmentação dos vínculos e dos próprios indivíduos, o distanciamento e mesmo a exclusão em relação à sociedade como um todo (CASTORIADIS, 1990 e 1996; BAUMAN, 1993). "Qualquer que seja a natureza dos laços na comunidade estética, eles não ligam: são literalmente laços sem conseqüências. Tendem a se dissolver (...) para compensar a ausência de recursos individuais ou a impotência” (BAUMAN, 2001, p.71).

\section{CONCLUSÃO}

Este deslocamento do espírito de corpo aparece como uma conseqüência inelutável da extensão da comunidade estética, que, reforçada pelas solicitações sensoriais contínuas, pela onipresença das telas nas sociedades contemporâneas, amplia o isolamento corporal, e também o social e psíquico, a precarização psíquica dos indivíduos. As sensações contínuas atingem o corpo e sua representação, provocando o automatismo reflexo, a compulsividade, a falta do tempo necessário ao exercício do pensamento e da reflexão. Provocam lassitude, uma fadiga crônica propícia a reforçar a tendência à dessubjetivação e à dessimbolização. ${ }^{16}$

\footnotetext{
${ }^{15}$ Este tipo de análise se aplica às formas de individualismo nas democracias; ela se mostra mais difícil para certas formas de comunitarismo presentes nas democracias, particularmente em relação às afirmações identitárias e em relação ao sentido.

${ }^{16}$ Sobre a questão dos fluxos e solicitações contínuas, ver Illich (2004). Em particular: "Surveiller son regard à l'âge du show" (1993); "Passé scopique et éthique du regard. Playdoyer pour l'étude historique de la perception oculaire” (1995). Ver, também, Revue Française de psychosomatique,
} 
Confrontamo-nos, hoje, com formas paradoxais e inéditas de vínculo e de comunidade: a valorização constante e extrema do eu, "fabricando" de maneira contínua o corpo; a extensão corporal ao provocar a recusa dos limites apresenta-se como indissociável de uma relação ora formal ora indistinta com o outro. Os desequilíbrios sensoriais, relacionados ao declínio do contato e à perda geral dos sentidos, que se traduz na busca de contatos sem contato, abre-se então a relações de força de extrema violência, a um corpo-a-corpo, a um face-a-face entre fortes e fracos. A recusa da relação com os limites, a negação de formas de ritualização e de separação dos corpos e dos espíritos, específica da comunidade estética, é igualmente própria às lógicas sectárias (HAROCHE, 2001).

Pensávamos saber o que é o corpo. Atualmente, somos levados a repensar certas questões, fundamentais e elementares, formuladas por Durkheim: a energia, a agitação permanente e não cristalizada, a fusão, fatores que se revelam ameaçadores e destrutivos do psiquismo (DURKHEIM, 1915/1998). Para além da relação com o limite, de sua importância ou negação, é o tipo de vínculo de contato psíquico, mental, psicológico e físico, involuntário ou deliberado, que oscila entre a fusão e o medo do contato - que se encontra hoje no cerne do espírito de corpo e de sua deriva.

Recebido em 15/3/2006. Aprovado em 15/4/2006.

\footnotetext{
"La fatigue”, n.24, Paris: PUF, 2003; Haroche (2004) e "Le sens du regard” (2004c). Diet, por sua vez, sublinha que, nos mecanismos sectários, "o sujeito é vítima de uma (...) dessubjetivação, cujo meio privilegiado é o ataque a todas às suas bases de apoio. Primeiramente, é a imagem do corpo e - o que nos parece aqui crucial - o mecanismo pulsional que são visados. Produzindo, por esgotamento e excitação, experiências limites que, freqüentemente, colocam em perigo a própria sobrevivência e que têm sempre como efeito despedaçar a imagem do corpo (...), trata-se de favorecer, pela perda da dimensão do real e da personalidade, a realização da dominação." Diet observa que "no fluxo sem limite nem obstáculo os significados desalinhados tornam-se absolutamente arbitrários. (...) Apenas o amor pelo senhor e a adesão ao discurso doutrinário parecem ainda propor um sentido num universo tornado caótico, sem fé nem lei, onde nada é verdadeiro, tudo é ao mesmo tempo permitido e proibido, onde tudo é, a todo momento, possível." Conclui afirmando que "esta confusão arcaica marca a desestabilização dos conteúdos de pensamento” (DIET, 1999a, p.57, 59). Ver, ainda, Anzieu (1995 e 1993).
} 


\section{REFERÊNCIAS}

ADORNO, T. (1951/1980). Minima moralia. Réflexions sur la vie mutilée. Paris: Payot.

et al. (1950/1964) The authoritarian personality. New York: Science Editions, Inc. (2v.)

ANZIEU, D. (1995) Le moi peau. 2 ed. Paris: Dunod. . et al. (1993) Les contenants de pensée. Paris: Dunod.

BAUMAN, Z. (1993) Life in fragments (Essays in postmodern morality). Oxford: Blackwell.

(2001) Community. Seeking safety in an insecure world. Oxford: Polity. (2003) Comunidade: A busca de segurança no mundo atual. Rio de Janeiro: Zahar.

BOISSIER, M. (1978) La religion romaine II, apud DURKHEIM, E. “Préface de la seconde édition", in De la division du travail social. 10 ed. Paris: PUF.

BOUHSIRA, J., DREYFUS, S. e FINE, A. (org.) (2004) "Caractères", in Monographies de la Revue Française de Psychanalyse, Paris: PUF, jan.

BOURDIEU, P. (1989). La noblesse d'Etat. Grandes Ecoles et esprit de corps. Paris: Minuit.

(1994). “A construção estatal dos espíritos”, in Raisons Pratiques. Sur la théorie de l'action. Paris: Seuil.

CASTORIADIS, C. (1990). Les carrefours du labyrinthe, Tome 3: Le monde morcelé. Paris: Seuil.

(1996). Les carrefours du labyrinthe, Tome 4: La montée de l'insignifiancel. Paris: Seuil.

DIET, Emmanuel (1999a) “Sectes”, in Débats de Psychanalyse, Revue Française de Psychanalyse.

. (1999b) "Pratiques sectaires et processus d’aliénation. Emprise et manipulation", in Revue Française de Psychanalyse.

(1930/1995) Malaise dans la culture, Paris: PUF.

DUMONT, L. (1991) L'idéologie allemande (Homo aequalis II). Paris: Gallimard.

DURKHEIM, E. (1915/1998) Les formes élémentaires de la vie religieuse. Paris: PUF.

(1978a) "Préface de la première édition", in De la division du travail social. 10 ed. Paris: PUF.

(1978b) “Préface de la seconde édition”, in De la division du travail social. 10 ed. Paris: PUF.

ELIAS, N. (1989/1996)The Germans, Power Struggles and the Development of Habitus in the Nineteenth and Twentieth Centuries. Cambridge /Oxford: M.Schröter / Polity Press.

ENRIQUEZ, E. (1999) “Le groupe: lieu de l'oscillation entre repli identitaire et travail de l'interrogation", in Débats de Psychanalyse, Revue Française de Psychanalyse, out.

FREUD, S. (1921/1997) "Psychologie collective et analyse du moi", in Essais de psychanalyse. Paris: Payot.

GAY, P. (1968/1995) Le suicide d'une République.Weimar 1918-1933. Paris: “Tel” Gallimard. 
(1993/1995) The cultivation of hatred. Paris: "Tel” Gallimard.

(1997) La culture de la haine. Hypocrisies et fantasmes de la bourgeoisie de Victoria à Freud. Paris: Plon.

GINZBURG, C. (1986/1989) Mythes, Emblèmes,Traces. Morphologie et histoire. Paris: Flammarion.

HALEVY, E. (1938/1990). L’ère des tyrannies. Etudes sur le socialisme et la guerre. Paris: "Tel" Gallimard.

HAROCHE, C. (2001) "Des formes et des manières en démocratie”, in Raisons Politiques, n.1. Paris: Presses de Science Po, fev.

(2004a) "Maneiras de ser, maneiras de sentir do indivíduo hipermoderno', in Ágora. Estudos em teoria psicanalítica, n2, v.VIII. Rio de Janeiro: Ed. Contra Capa, jul/dez.

(2004b) "Façons de voir, manières de regarder dans les sociétés contemporaines”, in Le sens du regard. Revue Communications, n.75, janvier, Paris, Seuil.

— (2004c) Le sens du regard. Revue Communications, n.75, janvier, Paris, Seuil.

HOLLIER, D. (1938/1995) Carta de Marcel Mauss à Elie Halévy, in Le collège de sociologie.Paris: Gallimard (Folio).

ILLICH, I. (2004) La perte des sens. Paris: Fayard.

LACQUEUR, W. (1984) Young Germany. A history of the German Youth Movement. New Brunswick: Transaction Books.

LEGENDRE, P. (1996) La fabrique de l'homme occidental. Paris: Fayard. . (1999) "La brèche. Remarques sur la dimension institutionnelle de la Shoah", in Sur la question dogmatique en Occident. Aspects théoriques. Paris: Fayard.

REICH, W. (1933/1998) Psychologie de masse du fascisme. Paris: Payot.

WEBER, M. (1919/1982) Le savant et le politique. Paris: Plon.

Claudine Haroche

ClHaroche@aol.com 